\title{
Explorations into the nature and function of compassion
}

\author{
To Appear in \\ Current Opinion in Psychology \\ by Paul Gilbert
}

Address for Correspondence:

Professor Paul Gilbert, PhD, FBPsS, OBE

Centre for Compassion Research and Training

University of Derby

College of Health and Social Care Research Centre

Derby, UK

DE22 1GB

Email: p.gilbert@derby.ac.uk 


\title{
Explorations into the nature and function of compassion
}

\author{
Abstract \\ Compassion has become a major focus for international research in prosocial behaviour. This \\ paper explores the evolutionary origins of caring and how recently evolved cognitive \\ competencies create human compassion. While some see compassion as linked to an \\ emotional or affective state, others root compassion in an evolved motivation and social \\ mentality. The paper will briefly explore fears, blocks and resistances to compassion, how \\ compassion can be understood as a social mentality and the increasing focus on \\ compassionate mind training.
}

\section{Introduction}

The last 30 years has seen a considerable upsurge of research into prosocial psychology (Bierhoff, 2005; Brown, \& Brown, 2015; Penner, Dovidio, Piliavin \& Schroeder, 2005). This includes explorations of altruism (Preston, 2013; Ricard, 2015), empathy (Decety, Bartal, Uzefovsky, \& Knafo-Noam (2016), morality and ethics (Sinnott-Armstrong, \& Miller, 2017) and compassion (Gilbert, 2005; 2017a; Seppälä, Simon-Thomas, Brown, Worline, Cameron \& Doty, 2017; Singer \& Bolz, 2012).

Origins. Given that there are evolutionary origins to many of our dimensions for prosocial behaviour (Brown, \& Brown, 2015; Buss, 2015; Dunbar, 2010, 2016), one dominant source of the basis of compassion evolved from mammalian caregiving of offspring (Brown \& Brown, 2015; Gilbert 1989, 2005, 2017b; Mayseless, 2016). The essence of mammalian infant caring behaviour is to be attentive to the distress and needs of another (e.g. infant), take actions to relieve distress, fulfil appropriate needs to prevent future distress and suffering, support growth, and prepare offspring for the challenges of independent living (Gilbert, 1989, 2009; Heard \& Lake 1989, Mayseless, 2016). Various mixtures (to varying degrees) of these behaviours are common in all caring relationships depending on closeness and context. However, caring for others is a costly behaviour, and therefore is generally constrained to the extent that it is more likely to be focused on kin and allies than non-kin and strangers (Buss, 2015; Loewenstein \& Small, 2007). Other evolutionary challenges that may have supported the evolution of caring behaviour revolve around being seen as an attractive ally and sexual partner (Gilbert 1989; 
Hardy \& Van Vugt, 2006) and supporting affiliative bonds (Dunbar 2016). In small hunter gatherer groups, the evolution of various forms of social intelligence - including language and empathy - would only be possible in the context of relatively safe, supportive and caring groups. There is archaeological evidence that in early hominid groups, old, injured and sick people were being cared for by their communities (Spikins, 2017).

From caring to compassion. What distinguishes compassion from basic nonhuman caring is that human compassion requires a particular set of cognitive competencies. These are competencies that have been evolving over the last 2 million years or so (Dunbar, 2016, Gilbert, 2005, 2017b; Suddendorf, 2018). They include a range of complex reasoning abilities that enable various forms of self-awareness, symbolic and systemic thinking, mentalising, reflection on the past, and behaviourally contingent predictions of the future called 'mental time travel' ('if I do that, then this is likely to be the outcome'; Suddendorf, 2018). In addition, humans have a form of knowing awareness that animals probably don't have. For example, no animal can deliberately choose to train (sometimes over many years) to improve their competencies in a certain area. Although earlier precursors of empathy certainly exist in other mammals (Preston, 2013) human empathy is on an entirely different (consciously aware insight) level (Bateson, 2017). Hence, the relationship between mammalian caring and human compassion can be depicted as in Figure 1

insert figure 1 about here

Definitions. When exploring 'difficult to identify' psychological phenomena, controversies of definition and phenomenology are common. Indeed, compassion has many different dictionary definitions, some involving pity and some involving sympathy. Schopenhauer and Nietzsche argued about compassion partly because they had quite different definitions. Nietzsche thought compassion was a poor focus for moral or helping behaviour because he saw it as a form of pity (Gilbert, 2017c). Some controversy exists over whether compassion is an affective state that motivates compassionate behaviour or is a primary motive that gives rise to emotion. For example, derived from an extensive review of the literature on compassion, Goetz, Keltner \& Simon-Thomas, (2010) suggest that “...compassion is a feeling that arises in witnessing another's suffering and that motivates a subsequent desire to help... This definition conceptualizes compassion as an affective state defined by a specific subjective feeling...." (p. 351; italics added). Building on this Goetz and Simon-Thomas (2017) consider the affective state of compassion has its own facial (sadness-like) and neurophysiological profiles. The 
suggestion is that it's this affective state that primes (motives for) helping. While this approach has generated considerable and important research, Barrett (2017) has raised concerns about whether any specific emotion actually exists in a rarefied form and suggests that emotions are constructed through context and history, making them very variable in terms of their triggering, textures and expressions and only loosely rooted in specific neurophysiologies. The issue is not whether or not these sadness-like emotional states can arise during experiences of compassion, as clearly they can, but rather whether they are the core element of compassion or some of its products.

Compassion as motivation. Buddhist approaches (Jinpa, 2015; Ricard, 2015) and motivational theorists (Gilbert, 1989; 2005; 2017b) focus less on the emotion and more on compassion as rooted in a caring motivational system. Motives are different to emotions in that they exist in the mind whether active or not, and can guide both conscious and unconscious processes (Bargh, 2017). Without a motive emotions couldn't be triggered. What triggers the motive of compassion are stimuli associated with distress and suffering, but the emotions associated with caring and compassion are complex and context dependent. For example, imagine a trained firefighter sitting in a café suddenly smelling smoke. They might become alarmed. Noticing where the fire is, and then entering the smoke-filled kitchen at the back of the café to save people working there, might be associated with anxiety and urgency. Seeing injustice may trigger anger or sitting with a dying person may create sadness. Consider too that the neurophysiological patterns generated in the firefighter, the campaigner against injustice, and the gentleness of the end-of-life counselling nurse will be quite different. Experiencing the flourishing of someone who has received our compassion may create joy; inadvertently hurting someone may trigger guilt. In all cases the stimulus trigger is the actual or potential for suffering/harm. Compassionate behaviours also vary according to the context and function. For example, a firefighter smelling smoke, a mother empathically soothing her child after a bad dream, and a consoling nurse will feel and behave very differently. It is also clear that people can behave compassionately for both rational and moral reasons (Loewenstein, \& Small, 2007). Important too is that motives also have seeking functions, e.g. we can seek out friends, sexual or status opportunities. Compassion can also lead us to seek out ways to act compassionately in the world linked to our identity. What unites all of these examples is engagement with distress and suffering and wish to alleviate and prevent it.

Many of the older contemplative traditions, that have focused on the cultivation of compassion, emphasise the motivation to help others and avoid causing harm. These include Jainism and 
Buddhism (particularly the Mahayana tradition). Monotheistic religions also claim this sentiment as central to their tradition. Combining Eastern and Western traditions of compassion, Gilbert \& Choden (2013) defined compassion as a motivation that orientates to: '.... a sensitivity to suffering in self and others with a commitment to try to alleviate and prevent it' (p. 94). This definition includes the issue of others and self and also includes the issue of compassion as being focused on prevention. A number of implications follow from this definition. First, the deliberate turning towards and tuning into suffering requires there to be a degree of motivation, willingness, courage and distress tolerance. This is true for working with the suffering of others and oneself. The second element addresses the issue of alleviation and prevention and here compassion inspires and invites dedication to acquire the skills to learn how to relieve and prevent suffering. This is another facet that makes it different from nonhuman caring. For example, if I see somebody fall into a fast-flowing river and wish to save them by jumping in, that will turn out to be foolish if I can't swim. Human compassion is not just an automatic response to suffering, a wish to be helpful, but involves a discernment, a reasoning process of what is best to do. Human compassion therefore involves the motivation to learn how to be helpful (as for example in the caring professions). In the contemplative traditions that dedication is with one's own mind, to understand the nature of mind and the illusions of self, in order to (compassionately) free others from the suffering caused by such illusions. This is called Bodhicitta (Tsering, 2008). So at the core of compassion is courage and dedication.

The motivation for compassion can therefore give rise to a sense of an identity, a self one tries to become and live by; a compassionate self (Gilbert 2005, 2009, Jinpa, 2015). The compassionate self would therefore be linked to mindfully living in such a way that one tries to be helpful and not harmful and thus regulate other competing motives within oneself (Gilbert, 2009). To accomplish this one may practice developing one's compassionate mind, with meditations, thought and behavioural practices that stimulate various physiological mechanisms that facilitate compassion (such as the frontal cortex and vagus nerve for example -- see below). Linked to a compassionate self-identity may be other dispositions that focus on helping. For example, in Hawaii there is a word kahi.au which means 'To give generously or lavishly with the heart and not with expectation of return' (Kirby, personal communication). Indeed, although rarely discussed, the desire to be helpful without expecting or wishing reciprocation can be central to compassion. As an aside humans excel at this, especially the 
desire to teach and share (Gilbert, 1989), and as evidenced by the many millions of Internet sites sharing 'how to do/learn' tutorials.

As a motivation, compassion has to compete with other motives (Huang, \& Bargh, 2014), many of which are unconscious (Bargh, 2017). These can be motives for competitive behaviour focusing on self-interest, and approval/prestige seeking within a group or only kin and reciprocal relationships, and tribal/group support (Buss, 2015). Hence, it is well known that we lavish huge resources on our own children even while we know thousands of children die every day of starvation, and many millions grow up in the slums of the world. We are more likely to save our own children from a fire than the 50 in the room upstairs. We are more likely to help those we like than those we don't, those who are likely to be reciprocate than those who are not, those who we identify as like us and in our group in contrast to those who are outside our group. Part of the challenge of compassion therefore is to break through these evolved boundaries around caring and helping behaviour (Ekman \& Ekman 2017; Gilbert 2009, 2018; Loewenstein \& Small, 2007; Ricard, 2015).

Fears blocks and resistances (FBRs) As with any motivation compassion, and some of its dependent competencies such as (empathy or distress tolerance) can be feared, blocked or resisted (Gilbert \& Mascaro 2017). Fears relate to the consequences of becoming more empathically compassionate such as being overwhelmed by distress or feeling personally undeserving. Blocks can be related to maybe wanting to but not knowing how, or a lack of understanding of compassion or being in contexts where compassion is difficult. For example, bureaucracies of the health service can reduce time clinicians have to spend with their clients. Self-compassion, in the context of very critical families, can be difficult. Resistance is where individuals are not frightened nor blocked but simply don't want to be compassionate. For example, thinking why should we help immigrants? It's too costly. All forms of compassion training will need to be aware of, and have means of addressing, fears, blocks and resistances.

Compassion as a social mentality. Social motives that involve creating mutually reciprocal roles have been called social mentalities (Gilbert, 1989, 2014, 2017b). Hence, in compassion it's important to not only study the provider of compassion but also what happens in the recipient of compassion. This is especially important because a lot of compassion research is focused on the provision of compassion, whereas in the compassion focused therapies the focus is on being open to and experiencing receiving compassion either from oneself or from others (Gilbert, 2010; 2014; Kirby \& Gilbert, 2017). So, compassion can be understood as a reciprocal 
process where providers will be paying attention to the impact of their caring on others, and the receivers will be monitoring how helpful the providers are. A simple example is the degree to which a parent perceives the distress of an infant, seeks to provide comfort to soothe that infant, the degree to which the infant is indeed soothed by what the parent provides, and then how that causes changes in the parent and the reciprocal interacting pattern of relating. Social intelligence allows us to be very sophisticated in our capacities for assessing the changing flow of such interactions and hence how best to help others.

For these and other reasons compassion can be understood as an integrated flow involving compassion to others, becoming receptive to the compassion from others, and also selfcompassion; with measures available for these orientations (Gilbert et al., 2017). There is evidence that these are highly interactive (Hermanto et al., 2016). In some clinical contexts, individuals may be very blocked on being open to receiving compassion, fear closeness, feel isolated and lonely, and need to begin to experience compassion from a therapist before they can become self-compassionate.

Compassion, body and brain. Caring behaviour evolved with a complex suite of physiological systems such as changes to the autonomic nervous system and vagus nerve, the hormones of oxytocin and vasopressin, and circuits in lower brain areas and the frontal cortex. These evolved circuits, along with others, provide the physiological infrastructure for empathy and caring behaviour (see Brown \& Brown 2015; Gilbert 2017a; Seppälä et al., 2017 for reviews).

As noted above caring behaviour has to have a target (a recipient), and so there was a coevolution such that targets would be physiological changed by the care they received. Hence, it is now known that the quality of care and compassion that humans receive have major psychological and physiological impacts. Receiving compassionate care during early life impacts epigenetic development (Cowan, Callaghan, Kan, \& Richardson, 2016), a range of physiological and neurophysiological systems (Mascaro, Darcher, Negi, \& Raison, 2015) such as the immune system (Pace et al., 2009) brain development (Siegel, 2015) and various psychological processes including emotion regulation and self-confidence (Mikulincer \& Shaver, 2017).

Compassionate mind training and therapy. Compassion cultivation is core to all the contemplative traditions. Some traditions focus on mindfulness training as a platform for insight meditation (in pali called Vipassanā). This suggests that as the mind slows and settles 
it gains insight into the true nature of mind, the illusory nature of a separate self, enabling compassion to naturally arises. In the Mahayana tradition, however compassion is a target for training in its own right. Recently the Western science has seen a growth of research studying the impact of compassion training on a range of physiological, psychological and social processes (see Kirby, Tellegen, \& Steindl, 2017; Singer \& Bolz, 2012; Seppälä et al., 2017 for reviews). Some trainings focus primarily on self-compassion (Neff \& Germer, 2018) or compassion to others (Jinpa, 2015) or on integrated three flows of compassion (to self, from others, to others) (Gilbert 2009, 2010 Gilbert \& Choden 2013, Irons \& Beaumont, 2017). Lovingkindness meditation typically focuses on directing it to self and others including 'difficult' people (Mascaro, et al., 2015; Weng et al., 2017). Various forms of compassion training impact on various physiological systems (Mascaro et al., 2015), including the neuroendocrine and immune systems (Pace et al., 2009), specific neurophysiological pathways (Vrtička, Favre, \& Singer, 2017), and the autonomic nervous system (Kirby, Doty, Petrocchi \& Gilbert, 2017). Weng, et al., (2013) found that two weeks of compassion training (focusing on benevolent wishes for family, friends and difficult people) resulted in increased altruistic behaviour in a fairness giving scenario, and changes in neurophysiological mediators. Valk, et al., (2017) compared three forms of training linked to: 1 attention and mindfulness; 2 socioeffective (including compassion training) 3; socio-cognitive (including metacognition, empathy and perspective training). These trainings produce different neurophysiological changes according to the training engaged. This indicates that these different types of training are not neurophysiologically equivalent (Vrtička, et al., 2017). Matos et al., (2017) found that practising compassionate mind skills for two weeks resulted in a range of beneficial psychological changes associated with well-being and also changes in heart rate variability. In fact, there are now a range of compassion focused trainings, linked to different models, all of which have some evidence of effectiveness (Kirby \& Gilbert, 2017). Currently, however, this is the early days of research and some of the methodologies are poor, the training and supervision of the therapists uncertain, and fidelity to the model rarely clarified. Understandable enthusiasm must therefore be held in check until much more rigourous studies are forthcoming. It is likely that in the years to come compassionate mind trainings and therapies will need to articulate how they can produce physiological change. Reliance on selfreport and symptom change will not be enough.

There are a range of compassion focused therapies that are being developed for particular groups of individuals, such as those who have been traumatised, those with complex psychoses 
and depressions, eating and personality difficulties. Importantly, clinical and nonclinical populations have different fears, blocks and resistances to compassion requiring quite different steps and strategies for stimulating and cultivating compassion motivation systems (Gilbert, 2014). For example, in clinical populations, particularly those who might have experienced abuse in childhood, compassion can (early on) stimulate attachment mechanisms and thereby reactivate trauma memories. Compassion can sometimes trigger people into a recognition of having lived with a sense of loneliness for many years which activates a grief process that can be felt as overwhelming. Individuals with personality disorders especially narcissistic and psychopathic can be very resistant to compassion and some may have particular difficulties if the physiological infrastructures necessary for compassion are weak or absent (Gilbert, 2017) Importantly whether we see compassion as an emotion or a motivation has implications for compassion training in psychotherapy contexts. For example, a depressed mother may be very motivated to care for her children but is depressed partly because she has lost all feeling for them, feels disconnected and lacks a sense of an emotional bond. Compassion focused therapy would focus very much on her actual behaviours and motivation and not engage in trying to generate feelings of compassion in the first instance, because very clearly the depression has suppressed that. Trying to create compassion feeling in certain clients can make them more depressed when they struggle (and fail) to do it; compassion insight and compassionate behaviour are much easier starting places. Compassion focused therapies involve motivation switching; that is switching people out of a competitive, self-critical, shame-based, defensive motivational focus into care and compassion focused one that organises attention, thinking behaviour and physiological processes quite differently. However, in clinical populations the steps for such motivation switching can be complex (Gilbert, 2010; 2014). In fact, clients can gain confidence from recognising they can be motivated for compassion (they would like to be helpful rather than harmful) and can behave compassionately without feeling compassionate. If we rely on feelings to be compassionate we may be limited in bringing compassion into the clinic, and indeed into the very important crises in the world today (Loewenstein, \& Small, 2007).

\section{Conclusion}

Compassion evolved out of mammalian caring motivational system(s). As a social mentality it can be understood as a motivated reciprocal interaction process; a type of social dance created between individuals where one is a perceiver of distress, suffering and need with a commitment 
to try to address those domains, while the other is a signaller of suffering and need and seeking to elicit help from others, and responding in certain ways to help when given. Hence, the evolution of compassion is a co-evolved process. What turns mammalian caring into compassion is textured by human evolved cognitive capacities along with certain types of self and mind awareness abilities (Dunbar, 2016, Gilbert 2018).

It's also clear that compassion is contextually sensitive, where we are more likely to be compassionate to kin and friends than to enemies. Indeed, this motivational system can be turned off. Cases of domestic abuse, bullying, exploitation through to the tragedies of enjoyment of the Roman games, slavery, the holocaust, the Balkans and Rwanda, show all too clearly how easy it is to stimulate individuals to behave extraordinarily harmfully rather than compassionately. So, compassion also under pins forms of morality. For example, moral thinking can focus on rights, justice and fairness whereas compassion typically focuses on the avoidance of causing harm and the moral obligations of helping those who are suffering or less well off than ourselves. These two dimensions of moral thinking can at times be in conflict (Bateson et al., 1995). Also core to compassion are courage and dedication. Compassion (and compassionate values and moral) is not just automatic but something that can be deliberately chosen and worked at with a deepening of understanding overtime. Compassion does not need love (firefighters or doctors working with infections do not need to love, or even like those they are trying to help). The challenge of compassion research is to how to stimulate this basic motivation in all domains of life, be it within ourselves, within our relationships, organisations and of course in politics; what Ekman and Ekman (2017; Gilbert, 2018) call global compassion. 
Refs

Bargh, J. (2017). Before you know it: The unconscious reasons we do what we do. New York: Simon and Schuster

Barrett, L. F. (2017). How emotions are made: The secret life of the brain. Houghton Mifflin Harcourt.

Batson, C.D (2017). The empathy altruism hypothesis what and so what? In, Seppälä, E.M., Simon-Thomas, S., Brown, S.L., Worline, M.C., Cameron, C.D \& Doty, J.R. (eds). The Oxford handbook of compassion science. (p.27-40). New York: Oxford University Press.

Batson, C.D., Klein, T. R., Highberger, L. and Shaw, L.L. (1995). Immorality from empathyinduced altruism: When compassion and justice conflict. Journal of Personality and Social Psychology, 68, 1042-54.

Bierhoff, H. W. (2005). The psychology of compassion and prosocial behaviour. In, P. Gilbert (ed). Compassion:. Conceptualisations, research and use in psychotherapy (p. 169-179). London: Routledge Compassion (pp. 160-179). London: Routledge.

Brown, S. L., \& Brown, R. M. (2015). Connecting prosocial behavior to improved physical health: Contributions from the neurobiology of parenting. Neuroscience and Biobehavioral Reviews, 55, 1-17

Buss, D. (2015). Evolutionary psychology: The new science of the mind. Psychology Press.

Cowan, C. S. M., Callaghan, B. L., Kan, J. M., \& Richardson, R. (2016). The lasting impact of early- life adversity on individuals and their descendants: potential mechanisms and hope for intervention. Genes, Brain and Behavior, 15(1), 155-168.

Decety, J., Bartal, I. B. A., Uzefovsky, F., \& Knafo-Noam, A. (2016). Empathy as a driver of prosocial behaviour: highly conserved neurobehavioural mechanisms across species. Phil. Trans. R. Soc. B, 371(1686), 20150077.

Dunbar, R.I.M. (2010). The social role of touch in humans and primates: Behavioral function and neurobiological mechanisms. Neuroscience and Biobehavioral Reviews. 34, 260268.

Dunbar R. I. M. (2016) The social brain hypothesis and human evolution. Oxford research encyclopedia of psychology. Online Publication Date: Mar 2016 DOI:

10.1093/acrefore/9780190236557.013.44

Ekman, p \& Ekman, E. (2017). Its global compassion achievable? In, Seppälä, E.M., SimonThomas, S., Brown, S.L., Worline, M.C., Cameron, C.D \& Doty, J.R. (eds). The Oxford handbook of compassion science. (p. 41-49). New York: Oxford University Press

Gilbert, P. (1989/2016). Human nature and suffering. Hove: Lawrence Erlbaum Associates.

Gilbert, P. (2005)(ed.). Compassion: Conceptualisations, research and use in psychotherapy. London: Routledge.

Gilbert, P. (2010). Compassion focused therapy: The CBT distinctive features series. London: Routledge.

Gilbert, P. (2014). The origins and nature of compassion focused therapy. British Journal of Clinical Psychology, 53, 6-41. doi:10.1111/bjc.12043. 
Gilbert. P (2017a,)(ed). Compassion: Concepts, research and applications. London: Routledge

Gilbert, P. (2017b). Compassion as a social mentality: An evolutionary approach. In, P. Gilbert (ed). Compassion: concepts, research and applications. (p. 31-68). London: Routledge.

Gilbert, P. (2017c). Compassion: definitions and controversies. In, P. Gilbert (ed). Compassion: Concepts, research and applications. (p. 3-15). London: Routledge.

Gilbert, P. (2018). Living like crazy. York: Annwyn House.

Gilbert, P., Catarino, F., Duarte, C., Matos, M., Kolts, R., Stubbs, J., Ceresatto, L., Duarte, J., Pinto-Gouveia. J \& Basran, J. (2017). The development of compassionate engagement and action scales for self and others. Journal of Compassionate Health Care, 4(1), 124, DOI 10.1186/s40639-017-0033-3

Gilbert, P \& Choden. (2013). Mindful compassion. London: Constable \& Robinson,

Gilbert, P \& Mascaro, J. (2017). Compassion: Fears, blocks, and resistances: An evolutionary investigation. In, Seppälä, E.M., Simon-Thomas, S., Brown, S.L., Worline, M.C., Cameron, C.D \& Doty, J.R. (eds). The Oxford handbook of compassion science. (p.388418). New York: Oxford University Press.

Goetz, J.E., Keltner, D., \& Simon-Thomas, E. (2010). Compassion: An evolutionary analysis and empirical review. Psychological Bulletin. 136, 351-374.

Goetz, J.E \& Simon-Thomas, S., (2017). The landscape of compassion definition and scientific approaches. In, Seppälä, E.M., Simon-Thomas, S., Brown, S.L., Worline, M.C., Cameron, C.D \& Doty, J.R. (eds). The Oxford handbook of compassion science. (p.316). New York: Oxford University Press.

Hardy, C. L., \& Van Vugt, M. (2006). Nice guys finish first: The competitive altruism hypothesis. Personality and Social Psychology Bulletin, 32(10), 1402-1413.

Heard, D \& Lake, B (1989). The challenge of attachment for care giving. London: Routledge

Hermanto, N., Zuroff, D.C., Kopala-Sibley, D.C., Kelly, A.C., Matos, M, \& Gilbert, P. (2016). Ability to receive compassion from others buffers the depressogenic effect of self-criticism: A cross-cultural multi-study analysis: Personality and Individual Differences 98, 324-332. doi.org/10.1016/j.paid.2016.04.055

Huang, J.Y. \& Bargh, J.A. (2014). The selfish goal: Autonomously operating motivational structures as the proximate cause of human judgment and behavior. Behavioral and Brain Sciences, 37, 121-175.

Irons, C \& Beaumont, E (2017). The Compassionate Mind Workbook: A step-by-step guide to developing your compassionate self. London: Little Brown.

Jinpa, T. (2015). A Fearless Heart. Why Compassion is the Key to Greater Well-Being. London: Little Brown.

Kirby. J.N., Doty, J., Petrocchi. N \& Gilbert. P. (2017). The current and future role of heart rate variability for assessing and training compassion. Frontiers. Public Health 5:40. doi: 10.3389/fpubh.2017.00040.

Kirby. J \& Gilbert, P. (2017). The emergence of the Compassion Focused Therapies. In, P. 
Gilbert (Ed). Compassion: Concepts, research and applications (p.258-285). London: Routledge.

Kirby, J.N., Tellegen, C.L., \& Steindl, S. (2017). A systematic review and meta-analysis of compassion-based interventions: Current state of knowledge and future directions. Behavior Therapy. http://dx.doi.org/10.1016/j.beth.2017.06.003.

Loewenstein, G., \& Small, D. A. (2007). The scarecrow and the tin man: The vicissitudes of human sympathy and caring. Review of general psychology, 11, 112-126.

Mascaro, J. S., Darcher, A., Negi, L. T., \& Raison, C. L. (2015). The neural mediators of kindness-based meditation: a theoretical model. Frontiers in psychology, 6, 109

Matos, M., Duarte, C., Duarte, J., Pinto-Gouveia, J., Petrocchi, N., Basran, J., \& Gilbert, P. (2017). Psychological and physiological effects of Compassionate Mind Training: A randomised pilot pontrolled ptudy. Mindfulness, 8(6), 1699-1712.

Mayseless, O. (2016). The Caring Motivation: An Integrated Theory: Oxford Oxford University Press.

Mikulincer, M \& Shaver, P.R. (2017b). An attachment perspective on compassion and altruism. In: P. Gilbert (ed). Compassion: Concepts, research and applications. (p. 187-202). London: Routledge.

Neff, K \& Germer, C.R. (2018). The Mindful Self-Compassion Workbook: A proven way to accept yourself, build inner strength, and thrive. New York: Guilford

Pace, T. W., Negi, L. T., Adame, D. D., Cole, S. P., Sivilli, T. I., Brown, T. D., Issa, M.J \& $\&$ Raison, C. L. (2009). Effect of compassion meditation on neuroendocrine, innate immune and behavioral responses to psychosocial stress. Psychoneuroendocrinology, 34(1), 87-98.

Penner, L. A., Dovidio, J. F., Piliavin, J. A., \& Schroeder, D. A. (2005). Prosocial behavior: Multilevel perspectives. Annual review of psychology, 56, 1-28.

Preston, S. D. (2013). The origins of altruism in offspring care. Psychological Bulletin, 139, 1305-1041.

Ricard, M. (2015). Altruism. The Power of Compassion to Change Itself and the World. London Atlantic Books.

Seppälä, E.M., Simon-Thomas, S., Brown, S.L., Worline, M.C., Cameron, C.D \& Doty, J.R (2017, eds.) The Oxford Handbook of compassion science. New York. Oxford University Press.

Spikins, P. (2017). Prehistoric origin: The compassion of distant strangers. In, P. Gilbert (Ed). Compassion: Concepts, research and applications. (p. 16-30). London: Routledge.

Siegel, D. J. (2015). The developing mind: How relationships and the brain interact to shape who we are. Guilford Publications

Singer, T., \& Bolz, M. (Eds.) (2012). Compassion: Bridging practice and science. http://www.compassion-training.org/. 
Sinnott-Armstrong, W., \& Miller, C. G. (2017). Moral psychology. Virtue and character. Volume 5. Cambridge: MIT Press.

Suddendorf, T (2018). Two features created the human mind. Scientific American. September,

Tsering, G.T., (2008). The Awakening Mind: The Foundation of Buddhist Thought Volume 4. London: Wisdom publications

Valk, S. L., Bernhardt, B. C., Trautwein, F. M., Böckler, A., Kanske, P., Guizard, N., Collins, D.L \& Singer, T. (2017). Structural plasticity of the social brain: Differential change after socio-affective and cognitive mental training. Science Advances, 3(10), e1700489.

Vrtička, P., Favre, P \& Singer, T. (2017). Compassion and the brain. In, P. Gilbert (ed). Compassion: Concepts, research and applications. (p. 135-150). London: Routledge

Weng, H. Y., Fox, A. S., Shackman, A. J., Stodola, D. E., Caldwell, J. Z., Olson, M. C., Rogers,G.M, \& Davidson, R. J. (2013). Compassion training alters altruism and neural responses to suffering. Psychological science, 24(7), 1171-1180. 
Figure 1 Caring, Human Social Intelligence and Compassion

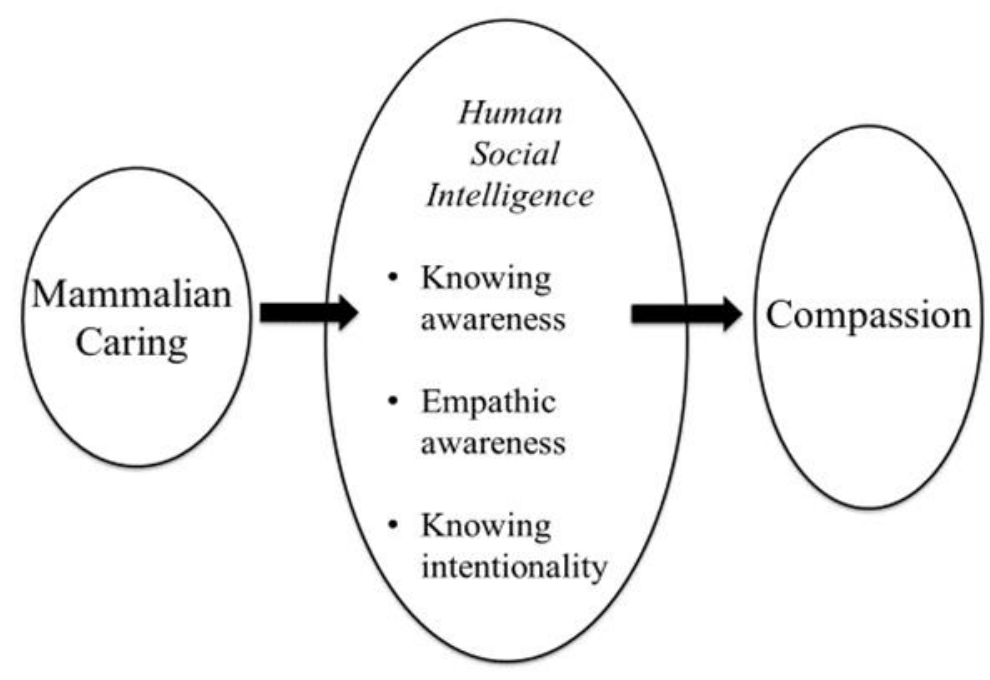

from Gilbert 2018 Living like Crazy with kind permission Annwyn House 